\title{
Deficiency of Arginine Esterase in Cystic Fibrosis of the Pancreas: Demonstration of the Proteolytic Nature of the Activity
}

\author{
G. J. S. RAO AND HENRY L. NADLER ${ }^{(23)}$ \\ Division of Genetics, The Children's Memorial Hospital, Department of Pediatrics, Northwestern University Medical \\ School, Chicago, Illinois, USA
}

\section{Extract}

Proteolytic activity, defined as the hydrolysis of peptide bonds involving the carboxyl group of L-arginine, in plasma of patients with cystic fibrosis, heterozygotes, and control subjects has been assayed using a fluorometric method with protamine as the substrate and fluorescamine as the reagent. The mean total proteolytic activity in plasma of patients with cystic fibrosis was approximately one-half the mean total activity in control subjects and heterozygotes. The mean proteolytic activity inhibited by soybean trypsin inhibitor in plasma of patients with cystic fibrosis was approximately one-third that of control subjects and heterozygotes.

The relationship of arginine esterase activity to proteolytic activity was investigated. The $\mathrm{pH}$ optimum and action of reversible and irreversible inhibitors were similar for both activities, suggesting that the arginine esterase activity and proteolytic activity represent similar catalytic entities. These findings are consistent with our hypothesis that the basic defect in cystic fibrosis may reside in the deficiency of a proteolytic enzyme which results in the accumulation of the various cationic macromolecular "factors" described by other investigators in serum of patients with cystic fibrosis.

\section{Speculation}

The demonstration of a deficiency of proteolytic activity as assayed by the hydrolysis of protamine, a cationic polypeptide, could explain the presence of ciliotoxic cationic protein or polypeptide factors in serum of patients with cystic fibrosis and may, in some unknown manner, be related to the clinical manifestations of the disease.

Cystic fibrosis (CF) is an autosomal recessive disorder characterized by failure to thrive, pancreatic insufficiency, and chronic pulmonary disease progressing to death in childhood or early adult life. The basic biochemical defect in this disease is unknown (12). We have reported previously $(13-15)$ that saliva and plasma of patients with CF are deficient in arginine esterase activity which is sensitive to inhibition by soybean trypsin inhibitor (STI). On the basis of these observations, we have postulated that the arginine esterase activity is a type of proteolytic activity involved in the hydrolysis of peptide bonds derived from the carboxyl groups of arginine. Previous attempts to demonstrate such proteolytic activity in plasma using an amide, polypeptide, or protein as substrate were unsuccessful, probably because of the insensitivity of the assay procedures. With the recent availability of fluorescamine, a reagent which can detect as little as picoequivalents of free amino groups (18), it has become possible to demonstrate proteolytic activity using protamine as substrate under the conditions of $\mathrm{pH}$ and ionic strength employed in the arginine esterase assay. Protamine, a polypeptide rich in arginine, provides many potential sites for attack by the enzyme, thereby increasing the sensitivity. This study demonstrates significant reductions in proteolytic activity in plasma of patients with $\mathrm{CF}$ and, in addition, provides evidence that the arginine esterase activity and proteolytic activity probably represent similar entities.

\section{MATERIALS AND METHODS}

STI, $N$-( $p$-toluenesulfonyl)-L-arginine methyl ester (Tos-Arg$\mathrm{OMe}), p$-hydroxymercuribenzoic acid (HMB), and 1-chloro-3tosylamido-7-amino-2-heptanone (Tos- $\mathrm{Lys}-\mathrm{CH}_{2} \mathrm{Cl}$ ) were obtained from Sigma Chemical Company. ( $p$-Nitrophenyl)- $p$-guanidobenzoate (NPGB) was purchased from Nutritional Biochemical Corporation.

Blood was obtained from 13 patients with cystic fibrosis, 7 obligate heterozygotes (parents of the CF patients in this study), and 10 pediatric control subjects. The patients and control subjects were between ages 3 and 15 years. In addition, samples from two patients with pulmonary and two patients with pancreatic diseases other than CF were studied. Normal sweat tests excluded the diagnosis of CF in these patients. The blood samples were collected from patients with $C F$ and their parents during routine visits to the Cystic Fibrosis Clinic of Children's Memorial Hospital. None of these patients had any evidence of liver disease.

Blood was collected using plastic equipment and contact with glass surfaces was avoided. Nine volumes of blood were mixed with 1 volume of $3.8 \%$ sodium citrate. The plasma was separated and treated with an equal volume of cold chloroform $(7,15)$ and centrifuged. The plasma layer was mixed, incubated with an equal volume of $0.1 \mathrm{mM}$ ellagic acid for $15 \mathrm{~min}$ at $24^{\circ}$ to activate the arginine esterases, and used immediately for assays. Plasma samples stored frozen at $-20^{\circ}$ before activation did not show any change in proteolytic activity. Unactivated plasma was dialyzed against $0.01 \mathrm{M} \mathrm{Na}_{2} \mathrm{HPO}_{4}, \mathrm{pH} 8.0$, at $4^{\circ}$ for $2 \mathrm{hr}$ to reduce the zero time blanks. Arginine esterase activity was assayed as reported previously $(7,15)$ using Tos-Arg-OMe as substrate.

The free amino group of protamine sulfate was blocked by dinitrophenylation essentially as published (5) except that the dinitrophenyl protamine was precipitated from the reaction with a large volume of acetone and washed repeatedly with $80 \%(\mathrm{v} / \mathrm{v})$ acetone, dry acetone, and ether. The air-dricd product was used as substrate.

The reaction mixture for the assay of proteolytic activity contained $2 \mathrm{mg}$ dinitrophenylated protamine $(5), 0.1 \mathrm{ml}$ activated plasma, and $0.04 \mathrm{mg} \mathrm{STI}$ (when needed) in $0.4 \mathrm{ml} 0.1 \mathrm{M} \mathrm{Na}_{2} \mathrm{HPO}_{4}$ and $0.15 \mathrm{M} \mathrm{NaCl}$ at $\mathrm{pH}$ 7.6. After incubation at $37^{\circ}$, the reaction was stopped by the addition of $0.4 \mathrm{ml} 10 \%$ trichloroacetic acid and centrifuged. Fifty microliters of the supernatant were mixed with $1.0 \mathrm{ml} 0.1 \mathrm{M}$ boric acid- $\mathrm{NaOH}$ buffer, $\mathrm{pH} 9.18$, and $0.2 \mathrm{ml}$ fluorescamine $(0.1 \mathrm{mg} / \mathrm{ml})$ in dry acetone was added with vigorous mixing. Fluorescence was determined in an Aminco-Bowman spectrofluorometer with an excitation wavelength of $390 \mathrm{~nm}$ and emission wavelength of $470 \mathrm{~nm}(5)$. The proteolytic activity was defined as the difference in fluorescence from an aliquot of the zero time blank and an aliquot obtained at the end of the incubation. 
The zero time blanks for plasma from control subjects, CF patients, or heterozygotes yielded relative fluorescence between 0.42 and 0.57 . When control plasma was used, approximately 5-8 times blank values were obtained at the end of the incubation. The fluorescence was converted to the equivalent of L-arginine using L-arginine as an arbitrary standard. The degree of proteolysis is expressed as microequivalents of L-arginine formed per hour per milliliter of plasma.

The comparative study of the properties of arginine esterase activity and proteolytic activity in control plasma was carried out using four different inhibitors: STI, a reversible inhibitor of many proteases; $\mathrm{HMB}$, a thiol group reagent and an inhibitor of many proteases such as cathepsin $\mathrm{B}(3)$; Tos- $\mathrm{Lys}-\mathrm{CH}_{2} \mathrm{Cl}$, a chloroketone analog of L-lysine which inhibits many proteolytic enzymes such as thrombin (9) and plasmin (10) by a stoichiometric irreversible reaction at the active site (these enzymes hydrolyze esters of lysine and arginine); and NPGB, an active site titrant of trypsin (6) which can potentially discriminate between binding sites specific to a guanidine group of arginine and the $\epsilon$-amino group of lysine in substrates. These reagents, particularly Tos- $\mathrm{Lys}-\mathrm{CH}_{2} \mathrm{Cl}$ or NPGB, have an "all or none" effect on the interfering proteolytic enzymes and offer a means of comparing enzymes which is superior to conventional procedures such as heat inactivation and separation on columns or zone electrophoresis.

The effects of STI $(100 \mu \mathrm{g} / \mathrm{ml})$, HMB $(0.1 \mathrm{mM})$, Tos-Lys$\mathrm{CH}_{2} \mathrm{Cl}(0.1 \mathrm{mM})$, and NPGB $(0.1 \mathrm{mM})$ were studied by preincubating buffered plasma with each of these inhibitory compounds for $15 \mathrm{~min}$ at $24^{\circ}$ before the addition of substrate. Suitable zero time blanks were run to correct for the interference, if any, of the inhibitors in the assay system. The concentrations of the inhibitors employed were sufficient to produce detectable effects on proteolytic activity. STI and NPGB were capable of inhibiting at even lower concentrations. Higher concentrations of HMB could not be employed in the phosphate medium because of its insolubility and production of turbidity. Glycylglycine buffer in which HMB is more soluble could not be used because of the interference of the free amino group of the buffer in the assay. For the same reason, higher concentrations of Tos- $\mathrm{Lys}-\mathrm{CH}_{2} \mathrm{Cl}$ were not employed. The preincubation time was restricted to $15 \mathrm{~min}$ as STI, HMB, and $\mathrm{NPGB}$ act almost instantaneously and $0.1 \mathrm{mM}$ Tos- $\mathrm{Lys}-\mathrm{CH}_{2} \mathrm{Cl}$ is known to produce detectable inhibition within this period. In

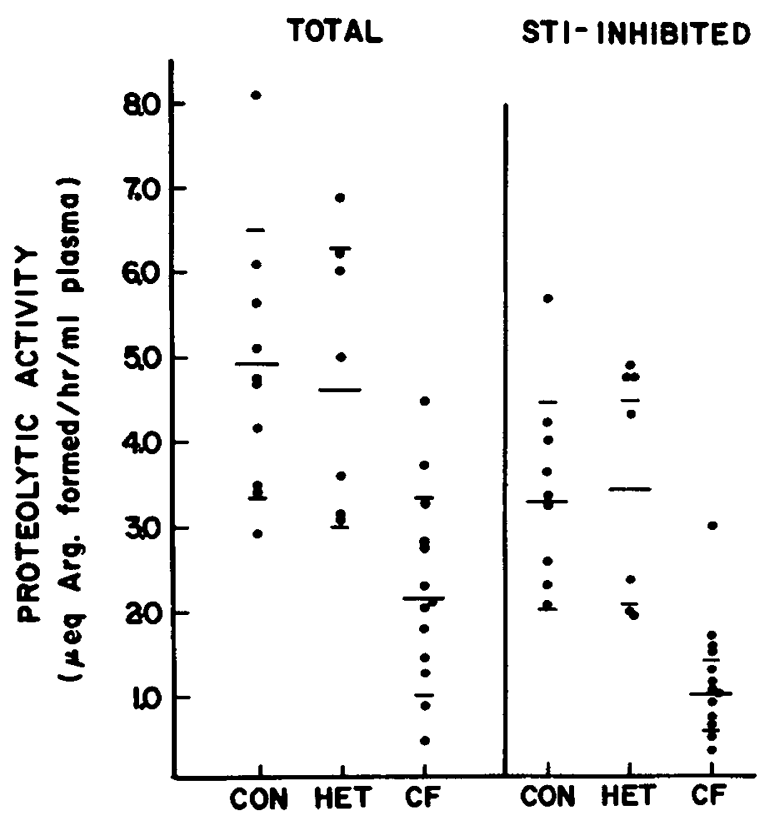

Fig. 1. Proteolytic acitivity in plasma samples assayed from patients with cystic fibrosis $(C F)$, control subjects $(C O N)$, and obligate heterozygotes (HET). The central large bars represent the mean and the small bars represent SD. STI: soybean trypsin inhibitor.
Table 1. Inhibition (\%) of activity with

$N$-(p-toluenesulfonyl)-L-arginine methyl ester and 2,4-dinitrophenyl protamine as substrates ${ }^{1}$

\begin{tabular}{lcc}
\hline & Tos-Arg-OMe & $\begin{array}{c}\text { 2,4-Dinitrophenyl } \\
\text { protamine }\end{array}$ \\
\hline STI $(100 \mu \mathrm{g} / \mathrm{ml})$ & 60 & 66 \\
HMB $(0.1 \mathrm{mM})$ & 0 & 0 \\
Tos-Lys-CH $\mathrm{Cl}$ & 10 & 10 \\
$(0.1 \mathrm{mM})$ & & 95 \\
NPGB $(0.1 \mathrm{mM})$ & 97 &
\end{tabular}

${ }^{1}$ STI: soybean trypsin inhibitor; HMB: $p$-hydroxymercuribenzoic acid; Tos-Lys- $\mathrm{CH}_{2} \mathrm{Cl}$, 1-chloro-3-tosylamido-7-amino-2-heptanone; NPGB: ( $p$ nitrophenyl)-p-guanidobenzoate.

addition, prolonged preincubations could not be employed as these enzymes continue to be activated in the presence of ellagic acid and, therefore, alter the standard conditions of the activation (7, $15)$.

\section{RESULTS}

Proteolytic activity was linear for $2 \mathrm{hr}$ and up to $0.2 \mathrm{ml}$ activated plasma in $0.4 \mathrm{ml}$ incubation mixture. The activity was optimal at pH 7.6 when assayed in $0.1 \mathrm{M} \mathrm{Na}_{2} \mathrm{HPO}_{4}$ buffer containing $0.15 \mathrm{M}$ $\mathrm{NaCl}$. Assays were performed routinely at $\mathrm{pH} 7.6$ for $60 \mathrm{~min}$ at $37^{\circ}$ using $0.1 \mathrm{ml}$ activated plasma. Activity in blood from a given individual drawn on separate occasions was reproducible within $10 \%$.

The mean total proteolytic activity in plasma of patients with CF $(2.18 \pm 1.22)$ was approximately one-half the mean total activity in control subjects $(4.93 \pm 1.59)$ (Fig. 1). The difference was significant at $P<0.001$. The mean activity of seven heterozygotes $(4.64 \pm 1.63)$ was significantly different from that of patients $(P<0.01)$. More pronounced differences were observed when the fractions of activity inhibited by STI were compared (Fig. 1). The mean activity in plasma from patients with CF $(0.99$ $\pm 0.44)$ was about one-third of that in control subjects $(3.27 \pm$ $1.30)$ or heterozygotes $(3.45 \pm 1.32)$ except in one case. (This patient was a member of one of the families previously reported by us to have had high arginine esterase activity (15)). No correlation was observed between the age or severity of the disease and the level of activity. Patients with either pulmonary or pancreatic diseases other than $C F$ had values similar to control subjects. No significant differences were observed between control subjects and obligate heterozygotes as a group when either mean total proteolytic activity or activity inhibited by STI were compared, although some heterozygotes did show activity intermediate in level between control subjects and patients.

The results of the comparative study of the properties of the two types of activities in control plasma, namely arginine esterase and proteolytic activities, are shown in Table 1. Both activities are optimal at pH 7.6 either in the presence or absence of STI. STI inhibits both activities to approximately the same extent, $60 \%$ versus $66 \%$. NPGB almost totally inhibited the activities. In contrast, neither arginine esterase nor proteolytic activities were significantly reduced in the presence of $\mathrm{HMB}$ or Tos- $\mathrm{Lys}-\mathrm{CH}_{2} \mathrm{Cl}$. Similar findings were noted with plasma from a patient with $\mathrm{CF}$.

\section{DISCUSSION}

These data indicate significant reductions in proteolytic activity, defined as the hydrolysis of peptide bonds involving the carboxyl group of arginine, in plasma of patients with CF. The differences in proteolytic activity between control subjects and patients was more pronounced when the fraction of activity inhibited by STI was compared. This observation is consistent with our previous report on the deficiency of arginine esterase activity in plasma of patients with CF $(14,15)$. 
Earlier mixing experiments $(13,15)$ have shown that the deficiency of arginine esterase in CF could not be attributed to the presence of inhibitors of either activation or function of these enzymes. The present data (Table 1) suggests that both arginine esterase and proteolytic activities represent similar catalytic entities. Therefore, the diminished proteolytic activity in $\mathrm{CF}$ plasma is presumably not due to the presence of inhibitors.

The virtual inability of $\mathrm{HMB}$ to inhibit the proteolytic activity suggests that the enzymatic activity does not belong to the class of thiol proteases such as cathepsin B (3). The inability of Tos-Lys$\mathrm{CH}_{2} \mathrm{Cl}$ to significantly inactivate the enzymes suggests that they do not represent the proteolytic enzymes involved in blood clotting such as thrombin (9) and plasmin (10), which also hydrolyze esters and peptides derived from arginine. The total inactivation by NPGB (6) is compatible with the preferential ability of plasma to hydrolyze esters of arginine in contrast with esters of lysine.

In our earlier studies, we suggested that the arginine esterase activity might represent kallikrein (15); however, Talamo et al. (17) and Lieberman and Littenberg (11) have provided data excluding a kallikrein deficiency. In the present work, we have also excluded thrombin and plasmin which also exhibit the type of proteolytic activity discussed in this report. Therefore, the nature of the proteolytic and arginine esterase activities remains to be determined.

Serum of patients with CF has been shown to contain a number of "factors" which induce dyskinesis in rabbit tracheal (16) and oyster ciliary preparations (4). These factors, cationic as judged by their chromatographic behavior on ion exchange columns (2), consist of either protein or polypeptide moieties, as they are inactivated by proteolytic digestion and heating $(1,2)$ and have molecular weights of approximately $10,000(2,8)$. It has been suggested that these factors may interfere with cellular processes of transport and absorption and, in some unknown manner, produce the clinical manifestations of CF. Therefore, it appears that the elevation of the levels of the factors may be the cause rather than the effect of cystic fibrosis. We have hypothesized previously (14, 15) that various serum factors found in CF represent either normal substances present in greater than usual amounts or metabolites which accumulate because of a primary enzyme deficiency. It is conceivable that the proteolytic activity described in this study which hydrolyzes protamine, a cationic polypeptide of molecular weight under 10,000, might represent such an enzyme deficiency. A deficiency of this activity would then result in elevated levels of factors found in patients with CF. Preliminary studies using normal cultivated skin fibroblasts have shown that these cells contain proteolytic activity similar to the activity described in this paper but at a very low level as compared with plasma. Attempts to develop more sensitive radioactive or immunochemical techniques are in progress to determine the levels of activity in cultivated skin fibroblasts of control subjects and patients with cystic fibrosis.

\section{SUMMARY}

Proteolytic activity, defined as the hydrolysis of peptide bonds involving the carboxyl groups of L-arginine, in plasma of patients with cystic fibrosis, heterozygotes, and control subjects, has been assayed using a fluorometric method. Significant reductions in proteolytic activity have been shown in plasma of CF patients as compared with control subjects or heterozygotes. More pronounced differences were observed when the fraction of activity inhibited by STI was compared.
As plasma of $C F$ patients has been found previously to be deficient in arginine esterase, the relationship between arginine esterase activity and proteolytic activity was investigated. The $\mathrm{pH}$ optimum and action of reversible and irreversible inhibitors were similar for both activities, suggesting that the arginine esterase activity and proteolytic activity represent similar catalytic entities. These findings are consistent with our hypothesis that the basic defect in cystic fibrosis may reside in the deficiency of a proteolytic enzyme which results in the accumulation of the various cationic macromolecular factors described by other investigators in serum of patients with cystic fibrosis.

\section{REFERENCES AND NOTES}

1. Barnett, D. R., Kurosky, A., Bowman, B. H., and Barranco, S. C.: Loss of ciliary inhibitory factor following proteolytic digestion and heat denaturation. Tex. Rep. Biol. Med., 31: 697 (1973).

2. Barnett, D. R., Kurosky, A., Bowman, B. H., Hutchison, T., Schmoyer, I., and Carson, S. D.: Cystic fibrosis: Molecular weight estimation of ciliary inhibitor. Tex. Rep. Biol. Med., 31: 703 (1973).

3. Barrett, A. J.: Human cathepsin B. I. Purification and some properties of the enzyme. Biochem. J., 131: 809 (1973).

4. Bowman, B. H., McCombs, M. L., and Lockhart, L. H.: Cystic fibrosis: Characterization of the inhibitor to ciliary action in oyster gills. Science, 167 : 871 (1970).

5. Brown, F., Friedman, M. L., and Troll, W.: Sensitive fluorescent determination of trypsin-like proteases. Biochem. Biophys. Res. Commun., 53: 75 (1973)

6. Chase, T., Jr., and Shaw, E.: Comparison of the esterase activities of trypsin, plasmin and thrombin on guanidobenzoate esters: titration of the enzymes. Biochemistry, 8: 2212 (1969)

7. Colman, R. W., Mattler, L., and Sherry, S.: Studies on the pre-kallikrein (kallikreinogen)-kallikrein enzyme system of human plasma. II. Evidence relating the kaolin-activated arginine esterase to plasma kallikrein. J. Clin. Invest., 48: 23 (1969).

8. Conover, J. H., Conod, E. J., and Hirschhorn, K.: Studies on the dyskinesis - factor in cystic fibrosis. Life Sci., 14: 253 (1974).

9. Glover, G., and Shaw, E.: The purification of thrombin and isolation of a peptide containing the active center histidine. J. Biol. Chem., 246: 4594 (1971).

10. Groskopf, W. R., Hsieh, B., Summaria, L., and Robbins, K. C.: Studies on the active center of human plasmin. The serine and histidine residues. J. Biol. Chem., 244: 359 (1969).

11. Lieberman, J., and Littenberg, G. D.: Increased kallikrein content of saliva from patients with cystic fibrosis of the pancreas. A theory of abnormal pathogenesis of abnormal secretions. Pediat. Res., 3: 571 (1969).

12. Lobeck, C. D.: Cystic fibrosis. In: J. B. Stanbury, J. B. Wyngaarden, and D. S. Fredrickson: Metabolic Basis of Inherited Disease, Ed. 3, Vol. 2, p. 1605 (McGraw-Hill, New York, 1972).

13. Rao, G. J. S., and Nadler, H. L.: Deficiency of trypsin-like activity in saliva of patients with cystic fibrosis. J. Pediat., 80: 573 (1972)

14. Rao, G. J. S, and Nadler, H. L.: Arginine esterase in cystic fibrosis of the pancreas. Pediat. Res., 8: 684 (1974).

15. Rao, G. J. S., Posner, L. A., and Nadler, H. L.: Deficiency of kallikrein activity in plasma of patients with cystic fibrosis. Science, 177: 610 (1972).

16. Spock, A., Heick, H. M. C., Cress, H., and Logan, W. S.: Abnormal serum factor in patients with cystic fibrosis of the pancreas. Pediat. Res., 1: 173 (1967).

17. Talamo, R. C., Colman, R. W., and Milunsky, A.: The plasma kallikrein-kinin system in cystic fibrosis. Pediat. Res., 6: 430/170 (1972).

18. Udenfriend, S., Stein, S., Bohlen, P., and Dairman, W.: Fluorescamine: A reagent for the detection of amino acids, peptides, proteins and primary amines in the picomole range. Science, 178: 871 (1972).

19. We thank Dr. Lewis Gibson for permitting us to study his patients and Greta Spells for technical assistance.

20. These studies were supported by grants from The National Foundation-March of Dimes, The Cystic Fibrosis Foundation, and The Chicago Community Trust.

21. G. J. S. Rao is the recipient of the Mary and Robert Wood Innovative Research Fellowship.

22. H. L. Nadler is the Irene Heinz Given and John La Porte Given Research Professor of Pediatrics.

23. Requests for reprints should be addressed to: Henry L. Nadler, M.D., Children's Memorial Hospital, 2300 Children's Plaza, Chicago, Ill. 60614 (USA).

24. Accepted for publication May 19, 1975. 